\title{
An Analysis of the Physical Mechanics Characteristics of a High-stacked Tailings Dam
}

\author{
Jingang He, Yaxian Zhang, Fei Yu, Zhenshi Guo \\ Jinduicheng Molybdenum Co., Ltd., Huaxian, China \\ Email address: \\ hejingang66@163.com (Jingang He)

\section{To cite this article:} \\ Jingang He, Yaxian Zhang, Fei Yu, Zhenshi Guo. An Analysis of the Physical Mechanics Characteristics of a High-stacked Tailings Dam. \\ Advances in Applied Sciences. Vol. 3, No. 4, 2018, pp. 52-58. doi: 10.11648/j.aas.20180304.12
}

Received: May 30, 2018; Accepted: September 30, 2018; Published: October 29, 2018

\begin{abstract}
From construction to operation, tailings have to go through a long period of time. With the passage of time, the early deposited tailings are gradually covered by the later deposited tailings, and the overburden on the accumulated tailings gradually increases. The different deposition time of tailings dam and the physical and mechanical characteristics of tailings in the sedimentary area are quite different, especially for high-stacked tailings dam. Therefore, it is very important to study the variation of physical and mechanical characteristics in the tailings of high-stacked tailings. In this paper, according to the early, middle and late operational stages, from 1989 to 2005, large scale drilling, in-situ testing and indoor testing were carried out on a certain upstream high pile tailings dam with a maximum thickness of $60 \mathrm{~m}, 100 \mathrm{~m}$, and $125 \mathrm{~m}$. The physical and mechanical indexes of tailings were divided according to the time and place of deposition, in order to find out the changing laws of physical and mechanical characteristics of the tailings sand around 16 years ago. According to the changing law of the physical and mechanical characteristics of tailings, this paper puts forward the statistical tailings parameters according to the different deposition time and location of tailings, the research results provide reference for choosing the calculating parameters in designing and analyzing tailings dams. Its research results have been applied in the protection of the tailings dam, the tailings reservoir environment protection, and the safety hidden danger management of tailings reservoirs.
\end{abstract}

Keywords: Tailings, Physical Mechanics Characteristics, Deposition Time, Zoning Statistics

\section{Preface}

The operating time of small tailings dams is short, and the parameters compiled according to the survey data for the district and the partition statistics are not too different; However, for small tailings dams with a long operating period, the physical and mechanical properties of tailings will also change over time. Compared with the small tailings dam, the High Stack Dam has the characteristics of higher accumulation dam body and longer operating time. With the passage of time, the overburden on the accumulative tailings gradually increases, and the physical and mechanical properties of the tailings vary greatly between the different deposition times and the sedimentary sites.

In the tailings characteristics study, over time, the consolidation and overloading in the tailings sediments have caused certain properties (strength, dry density, porosity, etc.) to change [1-3]. However, in tailings dominated by vulcanized minerals, shallow tailings are often in an alternating state of oxidation and reduction, and their heavy metal release, absorption, and desorption [4-7] not only have a certain impact on the environment, but also have many effects on the physical and mechanical properties of tailings. There are other parts of the tailings that have different patterns of change.

Therefore, when selecting the parameters of tailings dams dominated by sulphide minerals, such as seepage calculation, static force and dynamic stability calculation, the differences in physical and mechanical characteristics of tailings of high-pile tailings dams should be considered comprehensively: in addition to the beneficial effects such as increasing time and densification of deep tailings, the adverse effects of sulphide oxidation on the destruction of shallow tailings should also be considered. According to the data of the sediment time and different sediment location of tailings sand, the parameters are calculated to reflect the sedimentary characteristics of tailings dam.

A tailings pond is a deep cutting, erosion, and denudation of the middle and high mountain landforms. The upstream type damming is designed to have a total dam height of $164.5 \mathrm{~m}$ 
and a second-class tailings pond. It was put into operation in 1983. In 1989, 1997, and 2005, the largest tailings accumulation thickness reached about $60 \mathrm{~m}, 100 \mathrm{~m}$, and $125 \mathrm{~m}$ respectively. This paper intends to analyze the variation of physical and mechanical properties of the accumulated tailings sand in this tailings reservoir around 16 years ago.

\section{Characteristics of Tailings Over Time}

\subsection{Physical Mechanics Characteristics of Shallow Tailings}

\subsubsection{Variation of Shallow Tailings Over Time}

Fresh tailings (shallow tailings in sedimentary beaches during exploration, sampling depth 0-5 M) have different physical and mechanical properties from tailings that accumulate for a certain period of time and tailings that have the same position at different deposition times. See tables 1 and 2 . It can be seen that:

(1) Table 1: In 1989 compared with 2005, the dry density of weathered tailings decreased, the natural pore ratio became larger, the cohesive force decreased, and the permeability coefficient decreased.

(2) Table 2: The mechanical characteristics of shallow tailings in sedimentary beaches during different exploration periods have not changed significantly due to the unchanged hydraulic filling and deposition of tailings; There are differences in physical characteristics, such as the dry density of tailings in 1989 and the large permeability coefficient. The main reasons are changes in the original rock, changes in the grinding process, and the absence of sulfur concentrate, iron concentrate, and copper concentrate were not selected before 1989.

Table 1. Physical and mechanical characteristics of different deposition time of dam slope (depth of 0-5m).

\begin{tabular}{|c|c|c|c|c|c|c|c|c|}
\hline Time & category & $\begin{array}{l}\text { Dry density } \\
r_{d}, g / \mathrm{cm}^{3}\end{array}$ & $\begin{array}{l}\text { Natural Porosity } \\
\text { ratio e }\end{array}$ & $\begin{array}{l}\text { Compression } \\
\text { factor } \mathrm{a}_{1-2} \\
\mathrm{MPa}^{-1} \\
\end{array}$ & $\begin{array}{l}\text { modulus of } \\
\text { compression } \mathrm{Es}_{1-2} \\
\mathrm{MPa}\end{array}$ & $\begin{array}{l}\text { cohesive } \\
\text { strength } \mathrm{C}, \mathrm{kPa}\end{array}$ & $\begin{array}{l}\text { internal } \\
\text { frictional } \\
\text { angle } \Phi^{\circ} \\
\end{array}$ & $\begin{array}{l}\text { permeability } \\
\text { coefficient } \\
k_{v}, \mathbf{c m} / \mathbf{s}\end{array}$ \\
\hline \multirow{4}{*}{1989} & statistic figures & 21 & 21 & 21 & 21 & 19 & 19 & 21 \\
\hline & tail medium sand & 1.63 & 0.83 & 0.2 & 8.52 & 14.21 & 30.76 & $7.23 \times 10^{-3}$ \\
\hline & statistic figures & 13 & 13 & 13 & 13 & 12 & 12 & 13 \\
\hline & tail silty sand & 1.54 & 0.88 & 0.2 & 8.40 & 16.4 & 30.68 & $7.23 \times 10^{-3}$ \\
\hline \multirow{3}{*}{2005} & statistic figures & 17 & 17 & 15 & 15 & 10 & 10 & 8 \\
\hline & statistic figures & 10 & 10 & 8 & 8 & 7 & 7 & 3 \\
\hline & tail silty sand & 1.52 & 0.90 & 0.21 & 9.25 & 14.83 & 30.01 & $1.11 \times 10^{-4}$ \\
\hline
\end{tabular}

Table 2. Physical and mechanical characteristics of shallow tailings in different exploration stages.

\begin{tabular}{|c|c|c|c|c|c|c|c|c|}
\hline Time & category & $\begin{array}{l}\text { Dry density } \\
r_{d}, \mathbf{g} / \mathrm{cm}^{3}\end{array}$ & $\begin{array}{l}\text { Natural Porosity } \\
\text { ratio e }\end{array}$ & $\begin{array}{l}\text { Compression } \\
\text { factor } \mathrm{a}_{1-2} \\
\mathrm{MPa}^{-1} \\
\end{array}$ & $\begin{array}{l}\text { modulus of } \\
\text { compression } \\
\mathrm{Es}_{1-2} \mathrm{MPa} \\
\end{array}$ & $\begin{array}{l}\text { cohesive strength } \\
\mathrm{C}, \mathrm{kPa}\end{array}$ & $\begin{array}{l}\text { internal } \\
\text { frictional angle } \\
\Phi^{\circ}\end{array}$ & $\begin{array}{l}\text { permeability } \\
\text { coefficient } \\
\mathrm{kv}, \mathrm{cm} / \mathrm{s}\end{array}$ \\
\hline \multirow{2}{*}{1989} & statistic figures & 4 & 4 & 4 & 4 & 3 & 3 & 4 \\
\hline & Tail medium sand & 1.58 & 0.87 & 0.3 & 7.1 & 8.00 & 31.73 & $1.14 \mathrm{E}-02$ \\
\hline \multirow{2}{*}{2005} & statistic figures & 25 & 25 & 8 & 8 & 10 & 10 & 8 \\
\hline & Tail medium sand & 1.38 & 0.99 & 0.24 & 8.34 & 6.08 & 32.71 & $2.93 \mathrm{E}-03$ \\
\hline
\end{tabular}

\subsubsection{Physical Properties of Shallow Weathered Tailings}

The thickness of the weathered layer is about $5 \mathrm{~m}$. The gray-brown tailings represented by the weathering product $\mathrm{Fe}(\mathrm{OH})_{3}$ are mainly concentrated in the No.2-13 subdams(scattered in other areas), where the infiltration lines are buried shallow. Within 5 meters of the depth of the burial, it is often in a saturated-semi-saturated state.

Table 3 shows the composition of tailings in the range of 5 $\mathrm{m}$ with different drilling sites during exploration in 2005: upper gray-yellow, middle gray-brown (dark iron-containing minerals) and lower dark gray tailings. Table 4 shows that the upper tail sand is gray-brown (containing iron dark minerals) and the lower part is dark gray tail sand. Table 5 is an analysis of the upper and lower chemical elements of the weathering layer of the 7 sub-dams.

Table 3. Shallow tailings in different depth of dry density comparison table.

\begin{tabular}{|c|c|c|c|c|c|c|c|c|c|c|c|c|c|c|c|}
\hline \multirow{3}{*}{$\begin{array}{l}\text { Sampling } \\
\text { position }\end{array}$} & \multicolumn{3}{|c|}{ 116(No.4sub-dams) } & \multicolumn{3}{|c|}{$\begin{array}{l}\text { 213(No.13sub-dam } \\
\text { s) }\end{array}$} & \multicolumn{3}{|c|}{413 (No.13sub-dams) } & \multicolumn{3}{|c|}{ 318(No.8 sub-dams) } & \multicolumn{3}{|c|}{ 417(No.3sub-dams) } \\
\hline & \multicolumn{3}{|c|}{$3-5 \mathrm{~m}$ (Water level 3m) } & \multicolumn{3}{|c|}{$\begin{array}{l}5-5.2 \mathrm{~m}(\text { Water } \\
\text { level 6m) }\end{array}$} & \multicolumn{3}{|c|}{$3-3.2 \mathrm{~m}$ (Water level $5.2 \mathrm{~m})$} & \multicolumn{3}{|c|}{$\begin{array}{l}\text { 4.5-4.7 m(Water level } \\
2.9 \mathrm{~m})\end{array}$} & \multicolumn{3}{|c|}{$\begin{array}{l}2.5-2.7 \mathrm{~m} \text { (Water level } \\
1.3 \mathrm{~m})\end{array}$} \\
\hline & $\mathbf{r}_{\mathrm{d}}$ & e & $\mathbf{G}_{\mathrm{s}}$ & $\mathbf{r}_{\mathrm{d}}$ & e & $G_{s}$ & \multirow{4}{*}{$\begin{array}{l}\mathbf{r}_{\mathbf{d}} \\
1.54 / \text { tail } \\
\text { medium sand } \\
1.52 / \text { tail } \\
\text { medium sand } \\
1.49 / \text { tail } \\
\text { medium sand }\end{array}$} & e & $\mathbf{G}_{\mathrm{s}}$ & $\mathbf{r}_{\mathrm{d}}$ & e & $\mathbf{G}_{\mathbf{s}}$ & $\mathbf{r}_{\mathrm{d}}$ & e & $\mathbf{G}_{\mathrm{s}}$ \\
\hline \multirow{3}{*}{$\begin{array}{l}\text { Upper part } \\
\text { intermedia } \\
\text { te part } \\
\text { following } \\
\text { part }\end{array}$} & $\begin{array}{l}1.48 / \text { tail } \\
\text { medium sand }\end{array}$ & 0.954 & 2.90 & 1.43 & 0.985 & 2.83 & & 1.012 & 3.10 & 1.55 & 0.935 & 3.03 & \multirow{3}{*}{$\begin{array}{l}1.68 / \text { tail } \\
\text { medium sand } \\
1.63 / \text { tail } \\
\text { medium sand } \\
1.60 / \text { tail } \\
\text { Fine Sand }\end{array}$} & 0.878 & 3.05 \\
\hline & $\begin{array}{l}1.60 / \text { tail silty } \\
\text { sand }\end{array}$ & 0.967 & 3.15 & 1.48 & 1.03 & 3.0 & & 1.008 & 3.06 & 1.67 & 0.931 & 3.05 & & 0.885 & 3.07 \\
\hline & $\begin{array}{l}1.54 / \text { tail } \\
\text { medium sand }\end{array}$ & 0.861 & 2.87 & 1.46 & 0.97 & 2.87 & & 1.009 & 2.99 & 1.52 & 0.902 & 2.91 & & 0.867 & 2.99 \\
\hline
\end{tabular}


Table 4. The shallow layer of different depth of tailings dry density comparison table In 2005.

\begin{tabular}{|c|c|c|c|c|c|c|c|c|c|c|c|c|}
\hline $\begin{array}{l}\text { Drilling } \\
\text { number }\end{array}$ & \multicolumn{3}{|c|}{ 321( No.2sub-dams) } & \multicolumn{3}{|c|}{ 319( No.6sub-dams) } & \multicolumn{3}{|c|}{ 218( No.2 sub-dams) } & \multicolumn{3}{|c|}{ 415(No.8 sub-dams) } \\
\hline $\begin{array}{l}\text { Upper } \\
\text { sampling }\end{array}$ & \multicolumn{3}{|c|}{$0.7-0.9 \mathrm{~m}$ (Water level6.5) } & \multicolumn{3}{|c|}{$0.5-0.7 \mathrm{~m}$ (Water level $1.7 \mathrm{~m})$} & \multicolumn{3}{|c|}{ 1-6m(Water level 6m) } & \multicolumn{3}{|c|}{$1-1.2 \mathrm{~m}$ (Water level $2.1 \mathrm{~m})$} \\
\hline category & $\begin{array}{l}\text { Dry } \\
\text { density } \\
\mathrm{r}_{\mathrm{d}} / \mathrm{cm} / \mathrm{s}\end{array}$ & $\begin{array}{l}\text { Porosity } \\
\text { ratio } \\
\text { e }\end{array}$ & $\begin{array}{l}\text { specific } \\
\text { gravity } \\
\text { Gs }\end{array}$ & $\begin{array}{l}\text { Dry density } \\
\mathrm{rd} / \mathrm{cm} / \mathrm{s}\end{array}$ & $\begin{array}{l}\text { Porosity } \\
\text { ratio } \\
\text { e }\end{array}$ & $\begin{array}{l}\text { specific } \\
\text { gravity } \\
\text { Gs }\end{array}$ & $\begin{array}{l}\text { Dry density } \\
\mathrm{rd} / \mathrm{cm} / \mathrm{s}\end{array}$ & $\begin{array}{l}\text { Porosity } \\
\text { ratio } \\
\text { e }\end{array}$ & $\begin{array}{l}\text { specific } \\
\text { gravity } \\
\text { Gs }\end{array}$ & $\begin{array}{l}\text { Dry } \\
\text { density } \\
\mathrm{rd} / \mathrm{cm} / \mathrm{s}\end{array}$ & $\begin{array}{l}\text { Porosity } \\
\text { ratio } \\
\mathrm{e}\end{array}$ & $\begin{array}{l}\text { specific } \\
\text { gravity } \\
\text { Gs }\end{array}$ \\
\hline Upper part & $\begin{array}{l}1.41 / \text { tail } \\
\text { silt }\end{array}$ & 0.945 & 2.74 & $\begin{array}{l}1.48 / \text { tail silty } \\
\text { sand }\end{array}$ & 0.908 & 2.83 & $\begin{array}{l}1.52 / \text { tail silty } \\
\text { sand }\end{array}$ & 0.892 & 2.87 & $\begin{array}{l}1.59 / \text { tail } \\
\text { silty sand }\end{array}$ & 0.898 & 3.02 \\
\hline $\begin{array}{l}\text { following } \\
\text { part }\end{array}$ & $\begin{array}{l}1.47 / \text { tail } \\
\text { silty sand }\end{array}$ & 0.957 & 2.87 & $\begin{array}{l}1.55 / \text { tail } \\
\text { medium sand }\end{array}$ & 0.895 & 2.93 & $\begin{array}{l}1.66 / \text { tail } \\
\text { medium sand }\end{array}$ & 0.842 & 3.06 & $\begin{array}{l}1.69 / \text { tail } \\
\text { Fine Sand }\end{array}$ & 0.919 & 3.25 \\
\hline
\end{tabular}

Table 5. Elements of the tailings weathered sample unit:\%.

\begin{tabular}{llllllllll}
\hline & Element & Ca & Cu & Fe & Mg & Mn & Mo & Ti & Zn \\
number & & 0.4945 & 0.0201 & 17.72 & 0.9838 & 0.0645 & 0.0708 & 0.3117 & 0.0161 \\
$\mathrm{~S}_{1}$ & 0.5987 & 0.0153 & 13.84 & 0.3676 & 0.0419 & 0.1004 & 0.3621 & 0.0092 & bronzing \\
$\mathrm{S}_{2}$ & & & & Grayish yellow \\
\hline
\end{tabular}

It can be seen that:

(1) Table 3 shows that the dry density, natural pore ratio, and specific gravity of the dark iron-containing minerals in the middle are mostly higher than those of the upper and lower tailings. The reason why the porosity ratio becomes larger and the density becomes larger is mainly due to the fact that at the strongest stage of weathering, the porosity water has a low $\mathrm{pH}$ value, has the ability to dissolve iron oxide, and dissolves sulfates, and is taken away by surface water or groundwater. The porosity ratio becomes larger; Due to the absorption of pyrite oxidation products, the heavy metals such as Mn and Mo in the tailings were clearly enriched [8], increase its density.

(2) Tables 3 and 4 show that shallower tailings, which are exposed on the surface of iron-containing tailings, are highly oxidized and weathered, and in the strongest stage of weathering (desorption), sulphate and heavy metal ions in tailings are dissolved. Most of them are taken away by surface water. Therefore, there is a phenomenon in which the porosity ratio becomes larger and the density becomes smaller.

(3) According to the results of exploration in 1989, the tailings in the same position in Table 4 are dominated by tailings. Due to weathering, tailings are weathered and decomposed. In 2005, tailings and tailings are mainly fine particles.

(4) Table 5 shows that the weathered layer material is dominated by Fe elements. According to the experiment, a solution containing ferrous ions was added to the experiment column at a flow rate of about $0.75 \mathrm{ml} / \mathrm{min}$. The $\mathrm{pH}$ of the solution was basically maintained at about 7.0. With the increase of time, the total permeability coefficient of the experiment column basically showed a declining trend [9]. This shows that the main reason for the decrease of the permeability coefficient of the tailings is that the ferrous ions produced by the oxidation of pyrite in the shallow oxidation zone and the oxidation transition zone remain in the tailings.

\subsection{Physical and Mechanical Properties of Deep Tailings in the Same Position}

Drilling was carried out in 1989, 1997 and 2005 at the same locations as the 4th and 8th sub-dams of the tailings dam. On the basis of considering the settlement of the dam body, sampling analysis was carried out in the same position. Taking drilling No. 2 as an example, the dry density, natural porosity ratio, permeability coefficient, direct fast shear adhesion and internal friction angle of sand in different deposition time were analyzed. See Figure 1 to Figure 5.

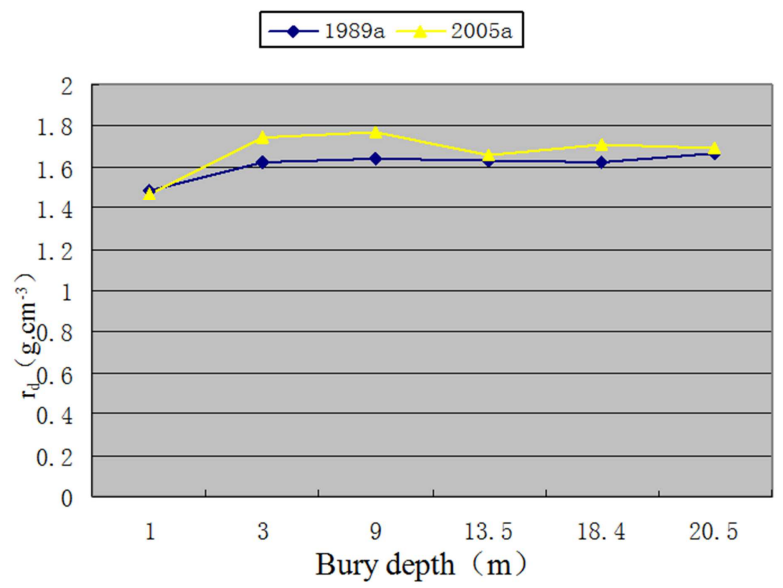

Figure 1. Relationship between dry density and buried depth of medium sand.

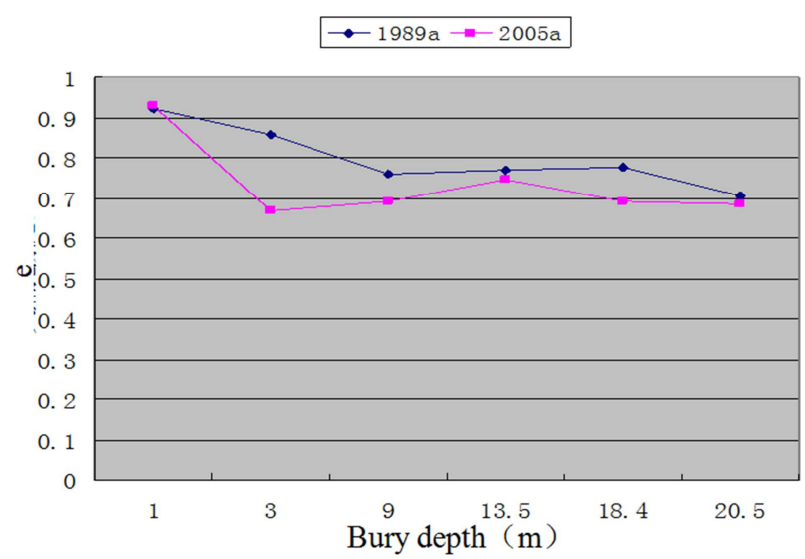

Figure 2. Relationship between natural porosity and buried depth of medium sand. 


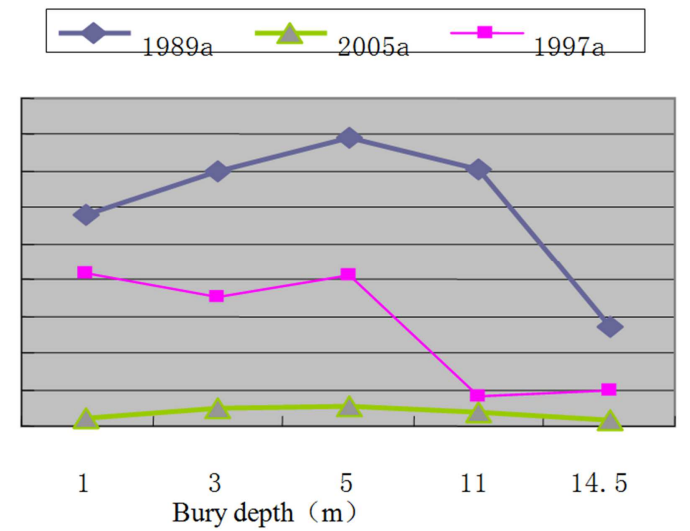

Figure 3. Relationship between permeability coefficient and buried depth of medium sand.

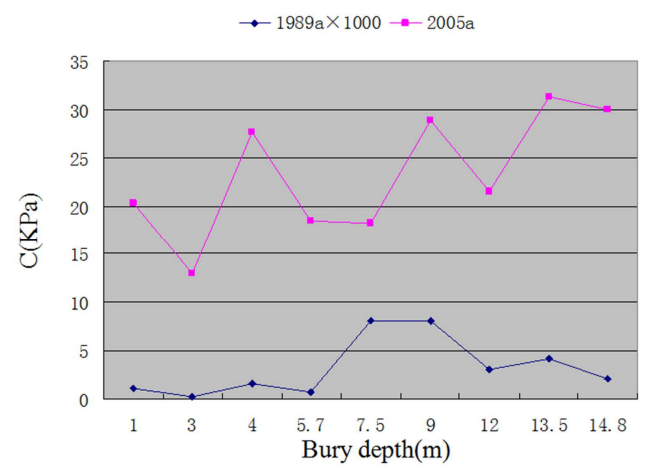

Figure 4. Relationship between cohesive force and buried depth of medium sand.

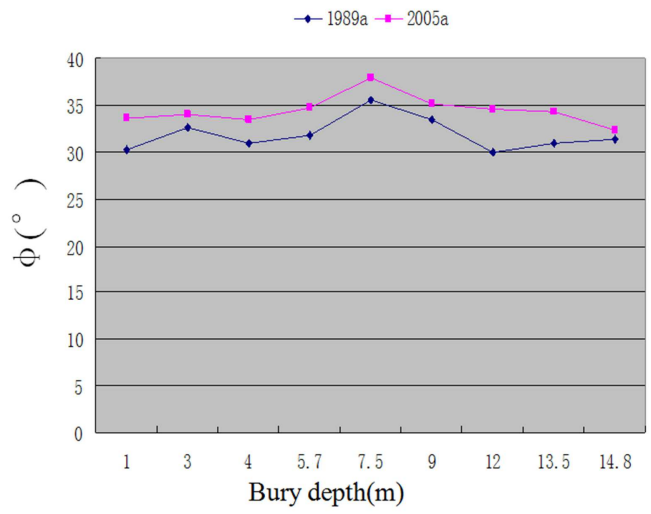

Figure 5. Relationship between internal friction angle and buried depth of medium sand.
(1) The dry density, porosity ratio and permeability coefficient of tailings have similar changes. The natural pores in the weathered layer with a depth of 0 to $5 \mathrm{M}$ become larger, and the natural density and dry density become smaller.

(2) The physical and mechanical parameters of the tailings are the most varied from about 5 to $15 \mathrm{~m}$ deep, and the changes in the depth of the tailings are gentle to about 25 meters deep. This is due to the loose and slightly dense state of $0-15 \mathrm{~m}$ tailings. $15-25 \mathrm{~m}$ transitions from slightly dense to medium dense, and below $25 \mathrm{M}$ is basically medium dense and dense.

(3) Within the same sedimentary period, with the increase of depth, the dry density increases, while the porosity ratio and permeability coefficient become smaller.

(4) With the increase of the age of deposition, the dry density increases, and the porosity ratio and permeability coefficient become smaller. The largest variation is about 5 to $15 \mathrm{~m}$ in depth, and the change tends to flatten around 25 buried depths. This also shows that the physical characteristics of tailings in the $0-25 \mathrm{~m}$ range have a close relationship with time, and below $25 \mathrm{M}$ is mainly affected by the depth of burial. The compaction of the deep tailings under the upper load and the drop of porosity ratio are also one of the reasons for the decline of the tailings permeability coefficient.

(5) Compared the data in 1989 with the data in 2005: Dry density of sand in the tail increased about $10 \%$ in the $5-15 \mathrm{~m}$ range and 5 to $7.3 \%$ in the $25 \mathrm{~m}$ range; Natural porosity ratio gradually stabilized after a reduction of about $23 \%$ in the 5-15m range;Direct quick shear: the cohesive force increases by double, and the internal friction angle increases by about $10 \%$.

(6) At the same age of deposition, with the increase of buried depth, tailings varied from loose, slightly dense, medium dense, and dense; The permeability coefficient gradually decreased. In the depth of $15 \mathrm{~m}$, the permeability coefficient decreased the most, and then, the permeability coefficient decreased steadily.

(7) The permeability coefficient decreases with the increase of deposition time at different sedimentary years and at the same sedimentary depth. In the depth of $15 \mathrm{~m}$, the infiltration coefficient decreased the most, and in depth of about $25 \mathrm{~m}$, the permeability coefficient decreased steadily. That is, at depths greater than $25 \mathrm{~m}$, the tailings are less affected by the deposition time and more affected by the upper cover.

\section{Determination of Physical and Mechanical Parameters of Tailings}

\subsection{Physical Properties of Tailings in Different Exploration Periods}

Table 6. Tables for the average physical indicators of the whole region at different times.

\begin{tabular}{|c|c|c|c|c|c|c|}
\hline \multirow{2}{*}{ Survey time } & \multirow{2}{*}{ category } & \multirow{2}{*}{$\begin{array}{l}\text { Natural density } \\
\rho d, g / \mathrm{cm}^{3}\end{array}$} & \multirow{2}{*}{$\begin{array}{l}\text { Porosity ratio } \\
\text { e }\end{array}$} & \multirow{2}{*}{$\begin{array}{l}\text { permeability coefficient } \\
\times 10^{-3}\end{array}$} & \multicolumn{2}{|c|}{ Fast-knot clipping } \\
\hline & & & & & C, MPa & $\Phi,{ }^{\circ}$ \\
\hline \multirow{3}{*}{1989} & tail medium sand & 1.88 & 0.801 & 4.71 & 5 & 33.4 \\
\hline & tail Fine Sand & 1.75 & 0.848 & 4.62 & 17 & 29.3 \\
\hline & tail silty sand & 1.83 & 0.814 & 5.9 & 10 & 30.5 \\
\hline \multirow{3}{*}{2005} & tail medium sand & 1.81 & 0.89 & 0.796 & 7.53 & 35.70 \\
\hline & tail Fine Sand & 1.85 & 0.87 & 0.409 & 12.13 & 33.22 \\
\hline & tail silty sand & 1.89 & 0.83 & 0.274 & 16.47 & 32.28 \\
\hline
\end{tabular}


Due to the accumulation of upstream tailings dams year by year, the statistics of the whole area include tailings in different sedimentary periods. Except for the reduction of permeability coefficient, the physical properties of tailings are not obvious. There is no reflection that the density of tailings changes with time, and the physical and mechanical properties of different sedimentary areas change due to weathering of surface tailings. See table 6.

\subsection{Determination of the Partition of Parameters}

\subsubsection{Tail Dam Rising Speed}

Before 1995, the annually average increasing speed of the dam surface was $4.67 \mathrm{~m}$. Since the two mineral treatment plants jointly delivered tailings in 1995, the annually average increasing speed of the dam surface was $4.13 \mathrm{~m}$. The Lixi tailings dam came into use in 1983. In 2013, it reached the originally designed elevation of $1300 \mathrm{~m}$ (total dam height of $164.5 \mathrm{M}$ ), and the dam body rose at a rate of about $4.14 \mathrm{~m}$ per year.

\subsubsection{The Relationship Between the Compactness of Tailings and the Depth of Burial}

According to the size of particle size, the tailings of the Lixi tailings dam can be divided into five kinds of tailings: tail medium sand, tail fine sand, tail silty sand, tail silty, tail silty clay. The main soil layer is tail medium sand and tail silty sand, its continuous thickness reaches $10.00 \sim 63.00 \mathrm{~m}$ and $10.00 \sim$ $64.00 \mathrm{~m}$, respectively. Take the tail medium sand and tail silty sand as an example, the relationship between the standard number of hits $\mathrm{N}$ (times) and the depth $\mathrm{H}(\mathrm{M})$ in the dam area is shown in Figure 6-9.

It can be seen that:

(1) The standard penetration number of the dam outer slope is relatively large, while the beach surface in the reservoir is small, which is related to the grain size and deposition time of the dam slope.

(2) The number of standard penetration increases with the increase of the buried depth of the tailings, indicating that the tailings change slightly from top to bottom due to the increase of the tailings accumulation time and the increase of the overburden. In addition to the sand and tail powder sand on the beach, it is loose to slightly dense, and the others are mainly medium dense.

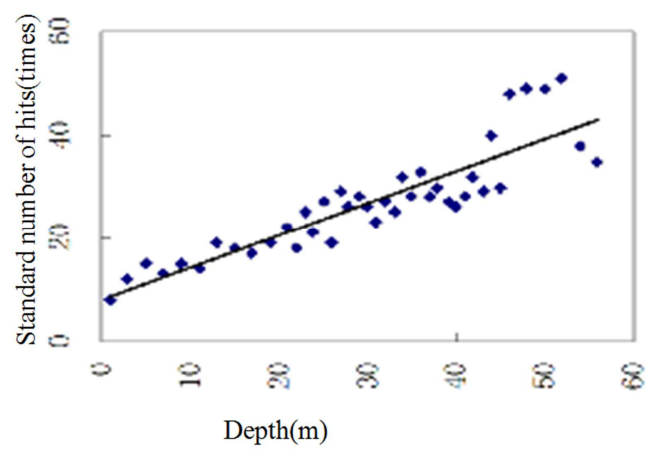

Figure 6. Diagram of tail medium sand standard number of hits changes with depth (dam slope).

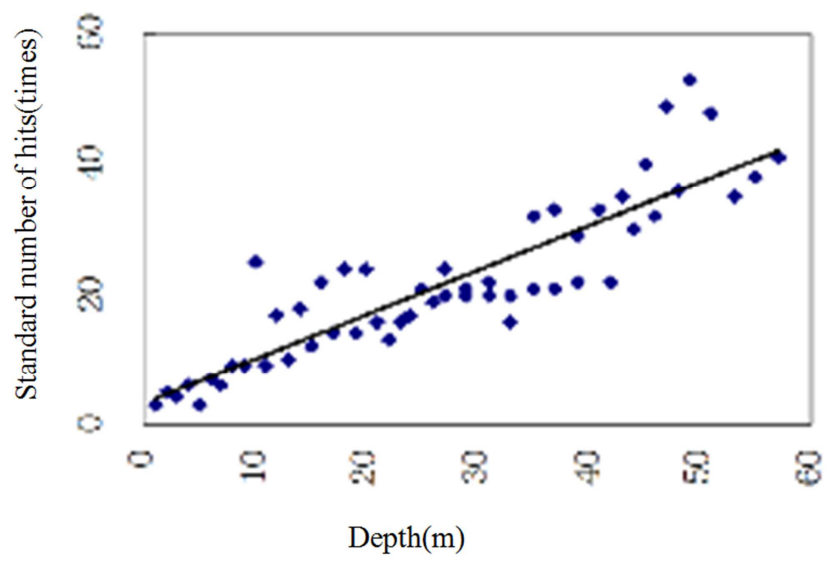

Figure 7. Diagram of tail medium sand standard number of hits changes with depth (deposited beach).

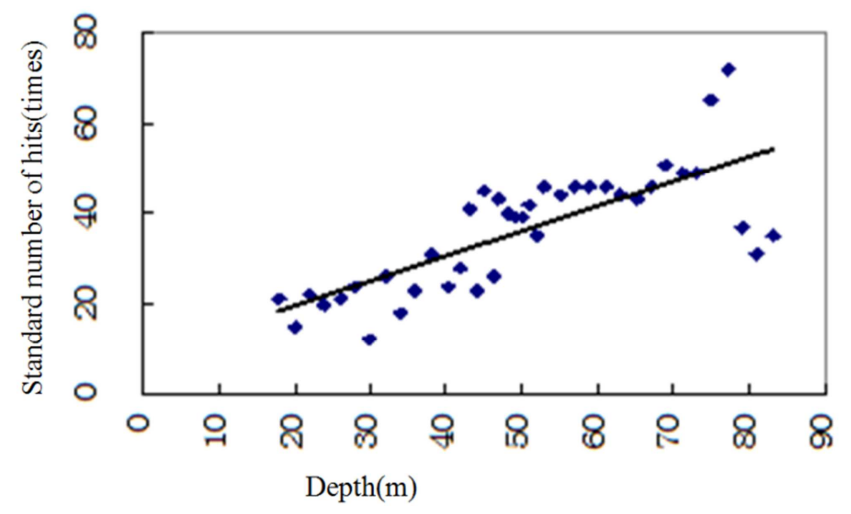

Figure 8. Diagram of tail silty sand standard number of hits changes with depth (dam slope).

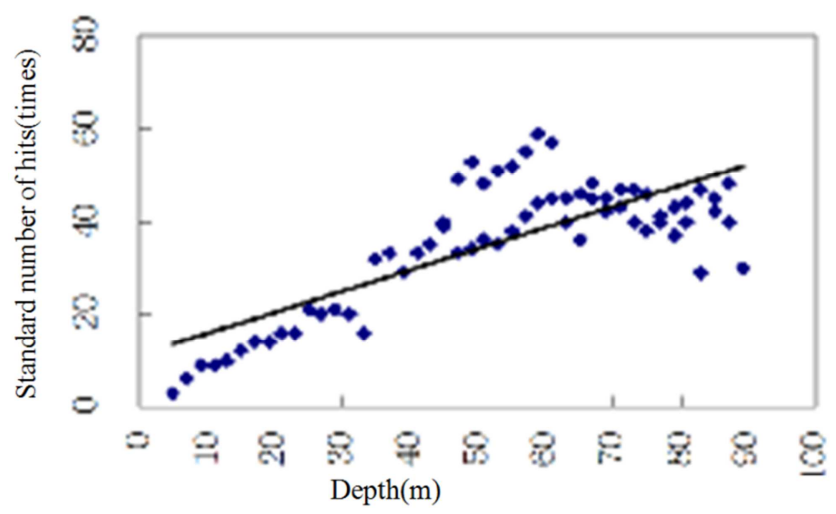

Figure 9. Diagram of tail silty sand standard number of hits changes with depth (deposited beach).

\subsubsection{Determination of the Statistical Area of Parameters}

(1) The operating period of the tailings reservoir is generally divided into three stages: early, middle, and late. In combination with the tailings reservoir, the survey period is the middle period. According to the characteristics of time changes, it can be divided into two parts: upper and lower statistics.

(2) The surface layer of the dam slope 0 to $5 \mathrm{~m}$ is a weathering layer, in which the middle and late accumulation of tailings is greatly affected by the pyrite wind turbine, and 
the physical and mechanical characteristics show a divergence, which can be measured separately.

(3) The upper dense state of the tailings of the tailings dam is loose, slightly dense and a small amount of medium dense, and the lower dense state is medium dense and dense. Therefore, the physical and mechanical indicators of the upper and lower soils were respectively counted. The statistical boundary is $20 \mathrm{~m}$ for the thickness of the tailings deposits and $30 \mathrm{~m}$ for the sedimentary beaches.

(4) The tailings dam can be divided into three parts: upper, middle, and lower. Statistical depth: dam slope 0-5m, 5-25m, below 25m; Dry beach $0-25 \mathrm{~m}$, below $25 \mathrm{~m}$.

\section{Conclusion}

(1) The physical and mechanical properties of shallow tailings have a close relationship with the oxidation of pyrite over time, which is the main reason for the decrease of the permeability coefficient of tailings.

(2) With the passage of time, the compaction of the deep tailings by the upper load, and the decline of the porosity ratio, are one of the reasons for the decline of the tailings permeability coefficient. At the depth of $25 \mathrm{M}$, the physical and mechanical properties of tailings change the most, and with the increase of burial depth, the physical and mechanical properties of tailings gradually become stable.

(3) According to the operation period of the high-stacked tailings dam, it is generally divided into three stages: early, middle, and late. The statistics of the upper, middle, and lower parts can reflect the operation characteristics of the tailings dam.

\section{Application of Research Results in Practice}

The results of this study have certain significance for the safety and environmental protection of tailings dams:

(1) Changes in the physical and mechanical properties of shallow tailings are related to the oxidation of sulphide minerals in tailings. Therefore, the content of pyrite is reduced by increasing the recovery of pyrite in the tailings.

(2) During the construction of tailings dams, the compaction of tailings dams and the effective coverage of dam slopes within a certain range can effectively reduce the weathering degree of shallow tailings.

(3) The results of the study on the seepage control of Lixi tailings dam using the physical and mechanical parameters of tailings measured by the zoning statistics are closer to the actual measurement results.

(4) Zoning statistics tailings parameters were successfully applied to the study of seepage control of Lixi tailings dam. The predicted flow rate of seepage is $5 \%$ different from the measured value [8].

\section{References}

[1] Cao Jing, Gong Xian-wei, Li Hong-xiang, Dai Zhi-hong. A Preliminary study on mechanism of chemical consolidation of Majiatian tailings TAILINGS' Panzhihua steel and ironplant [J]. Journal of GuilLin Institute of Technology, 2000, 20(2):147-150

[2] Li yuhong, Chen mengli, Li wenjun. A preliminary study on the change of the characteristics of a tailings sandy soil over time [J]. West-china Exploration Engineering, 2011, (2):21-22

[3] ZHANG Ya-xian, HE Jin-gang, GUO Zhen-shi. Study on tailings accumulation characteristics of high tailings dam [J]. China Molybdenum Industry, 2010, 34(5):8-12.

[4] LU long, WANG Ru-cheng, XUE Ji-yue, CHEN Jun and LU Jian-jun. The Surface Reaction of Sulfide Minerals and Its Application to the Study of Mine Environment [J]. Acta Petrologica Et Mineralogica, 2001, 20(4):387-391.

[5] ZHU Jibao, CHEN Fanrong, LU Long, xie xinghua. Heavy metal geochemistry behavior during the oxidation of the Fankou $\mathrm{Pb}-\mathrm{Zn}$ mine tailings in Guangdong province and the implications for environmental remediation of the mines $[\mathrm{J}]$. Acta cientiae Circumstantiae, 2005, 25(3):414-422.

[6] Kmaet G, Ohmoto H. The kineties of reaction bewteen Pyrite and $\mathrm{O} 2$ bearing water revealed from insitu motoring of DO, Eh, $\mathrm{pH}$ in a closed System [J]. Geochim. Coschim. Acta, 2000, 64:2585-2601.

[7] HE Jin-gang, ZHANG Ya-xian, GUO Zhen-shi. Environmental impacts and occurrence situation of pyrite in taling [J]. China Molybdenum Industry, 2013, 37(3):28-32.

[8] Guo zhenshi He jingang, Wu yanqing, Wu jun et al.. Study on extension of service and environmental protection by Lixi tailings pond [R]. Jinduicheng Molybdenum Group Co., Ltd., 2006. 6 .

\section{Biography}

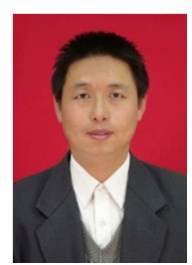

He jingang: Man, 1972-, Senior Geological Engineer, long-term geotechnical work and tailings research work.

SETTING: Jinduicheng Molybdenum Co., Ltd., huaxian, Shaanxi, China 